\title{
Notes sobre la flora del Pallars i l'alt Aran
}

\author{
Pere Aymerich ${ }^{1}$
}

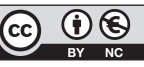

Data de recepció: 15 d'octubre de 2017

Data d'acceptació: 4 de novembre de 2017

Data de publicació: 22 de novembre de 2017

\begin{abstract}
Resum
Aportem noves dades florístiques del Pallars i l'alt Aran (Pirineus centrals), referides a tàxons rars en aquesta àrea o en el conjunt de Catalunya. Potamogeton $\times$ nitens Weber és citat per primera vegada de forma concreta a Catalunya. Persicaria minor (Huds.) Opiz i Xanthoselinum venetum (Spreng.) Soldano \& Banfi són novetats destacables per a la flora regional d'aquest sector dels Pirineus.
\end{abstract}

Paraules clau: flora; corologia; Pirineus; Catalunya; NE península Ibèrica

\begin{abstract}
Notes about the flora of Pallars and upper Aran valley (Pyrenees)
We provide new floristic data of Pallars county and the upper Aran valley (Central Pyrenees) about some taxa that are rare in this area or in whole Catalonia. We report for first time a concrete site of Potamogeton $\times$ nitens Weber in Catalonia. Persicaria minor (Huds.) Opiz and Xanthoselinum venetum (Spreng.) Soldano \& Banfi are outstanding novelties for the regional flora of this Pyrenean area.
\end{abstract}

Keywords: flora; chorology; Pyrenees; Catalonia; north-eastern Iberian Peninsula

\section{Introducció}

Aquest treball té com a objectiu exposar algunes dades florístiques més o menys interessants sobre la flora del Pallars i de la zona de capçalera de la vall d'Aran. Aquesta àrea forma part dels Pirineus centrals catalans, un sector que ha estat objecte d'una quantitat notable d'estudis botànics, però on encara es van trobant novetats amb una certa frequiència (Guardiola et al., 2011). Les informacions que s'aporten fan referència a tàxons rars o poc citats al sector d'estudi o bé al conjunt de Catalunya, entre els quals hi ha algunes espècies que es consideren amenaçades o estan protegides legalment. 


\section{Material i mètodes}

La informació referida a cada tàxon consisteix en una citació florística amb el format habitual i després un comentari més o menys extens que contextualitza l'interès relatiu de la citació. En cada citació s'indica, en aquest ordre: comarca, municipi, indret, quadrat UTM $1 \times 1$ (sempre dins el fus 31T i amb sistema de referència ETRS89), altitud, hàbitat i data d'observació (si s'han fet diverses observacions al lloc en un mateix període, només indiquem el mes o l'any). Els topònims de referència utilitzats són els de la base cartogràfica de l'Institut Cartogràfic i Geològic de Catalunya (<http://www.icgc.cat $>$ ), amb el nivell de detall considerat més adequat en cada cas. De les localitats marcades amb asterisc (*) es conserven plecs testimoni a l'herbari personal de l'autor, que properament seran dipositats a l'Herbari BCN. Els comentaris que segueixen la citació són molt diversos, segons els casos (singularitat de les poblacions locals, mida poblacional quan es tracta de tàxons molt rars o amenaçats...). En alguns casos de tàxons d'identificació complexa també hem considerat convenient incorporar-hi observacions sobre detalls morfològics.

La bibliografia que s'ha fet servir ha estat la que s'ha considerat convenient en cada cas. Una primera referència utilitzada per a avaluar l'interès relatiu de les troballes han estat dues bases de dades corològiques en línia (Base de Dades de Biodiversitat de Catalunya: <http://biodiver.bio.ub.es/biocat/>; Atles de la Flora dels Pirineus: <www.atlasflorapyrenaea.org>), que són citades com a BDBC i AFP, amb l'objectiu d'agilitzar la lectura. Les consultes a aquestes bases de dades s'han fet els mesos de setembre i octubre de 2017.

\section{Resultats}

Arctostaphylos alpina (L.) Spreng.

Pallars SobIrà: Alt Àneu, capçalera de la vall d'Àrreu, vessant obac entre l'estany del Muntanyó d' Àrreu i els clots de Rialba, CH3725, 2250-2300 m, matollars rasos de Dryas octopetala, en terreny pedregós calcari, 26-VIII-2016.

Planta àrticoalpina que a Catalunya — si s'exceptua l'Aran- només es coneixia de tres localitats de l'alt Pallars (Rivas-Martínez et al., 1991; Aymerich, 2008; AFP). Afegim una nova localitat amb una població important que se situa al massís de Beret, sector en el qual la seva presència ja havia estat documentada.

Asphodelus macrocarpus Parl. subsp. macrocarpus

PAllars SobIrà: La Guingueta d'Àneu, vessant al costat est de l'embassament de la Torrassa, CH4716, 950-980 m, relleixos d'un vessant rocós orientat a l'oest, sobre esquistos carbonatats, 4-V-2017; Llavorsí, vessant a la riba est del riu Noguera Pallaresa, CH5206, 820-850 m, relleixos d'un vessant rocós orientat a l'oest, sobre esquistos carbonatats, 4-V-2017.

Tàxon de distribució encara insuficientment coneguda a Catalunya, a causa de la confusió freqüent amb Asphodelus similars, i que ha estat indicat bàsicament dels Pirineus i Prepirineus orientals i dels Prepirineus centrals (Aymerich \& Sáez, 
2015). A les valls dels Pirineus centrals només havia estat citat, de forma una mica confusa, per Ninot et al. (2010) a la rodalia de Son (Pallars Sobirà), comentant que entre els A. albus Mill. sensu lato «almenys en alguns casos es tracta de la subsp. villarsii (Billot) I.B.K. Richardson \& Smythies» —un sinònim d'A. macrocarpus. Confirmem la presència d'aquesta espècie a la vall superior de la Noguera Pallaresa, on sembla tenir una ecologia diferent d'A. albus. A les dues localitats que aportem es feia en ambients força càlids i xeròfils del fons de vall, bé que en relleixos amb sòl més o menys profund. En canvi, totes les poblacions que hem observat en ambients de més altitud, mesòfils o mesoxeròfils, corresponen a A. albus subsp. delphinensis (Gren. \& Godr.) Z. Díaz \& Valdés. En canvi, en altres sectors de Catalunya en què $A$. albus és absent (Pirineus orientals, en particular), A. macrocarpus ocupa hàbitats de muntanya més humits.

\section{Botrychium matricariifolium (Retz) Koch}

Pallars Sobirà: Alins, entre Alins i Norís, CH6312, 1590 m, talús sota una coberta poc densa d'arbres caducifolis, en una zona d'antics camps i prats, 6-VII-2017.

Aquest pteridòfit circumboreal és molt rar als Pirineus, on se'n coneixen menys de deu poblacions, mentre que a la Catalunya administrativa es considera que està fortament amenaçat i les localitats publicades no arriben a cinc (Bou \& Manobens, 1982; Sáez et al., 2010; Pié \& Vilar, 2014). La seva presència al Pallars Sobirà, i concretament a la vall Ferrera, va ser detectada l'any 2010, bé que no es va publicar ni ha estat confirmada amb seguretat fins a 2017. El descobriment en aquesta zona és degut a Paul Cardy i un grup de viatgers naturalistes britànics, que en van observar un individu l'any 2010 i el van retrobar el 2013, però no els anys 2011 i 2012. Aquesta troballa es va considerar fiable, tot i no disposar de testimonis d'herbari ni gràfics, motiu pel qual el Parc Natural de l'Alt Pirineu, dins el qual es troba la localitat, va decidir emprendre un seguiment. Es va fer un primer control l'any 2014, que va ser negatiu, però amb un nou control el 2017 ha estat possible observar i documentar un individu. Aquesta planta està en un punt diferent de l'observada els anys 2010 i 2013, bé que a només $50 \mathrm{~m}$ de distància. L'hàbitat és similar al de la major part de poblacions pirinenques de l'espècie (arbredes mesòfiles en terreny silici, sovint assimilables a freixenedes). El fet d'observar només dos individus en un període de vuit anys suggereix que la població seria molt petita, però es tracta d'una planta de vida bàsicament subterrània, per a la qual les observacions a la superfície reflecteixen de forma poc fiable la població real.

\section{Cardamine flexuosa With.}

Pallars Sobirà: Ribera de Cardós, Estaon, cap a la borda de Gori, CH5317, $1320 \mathrm{~m}$, bosc de ribera, 2-X-2014.

Espècie molt rara al Pallars, on ha estat citada bàsicament a l'alt Àneu (BDBC). A la vall de Cardós tan sols en coneixem una dada al bosc de Boavi (Gruber, 1978). 


\section{Cochlearia pyrenaica DC.}

Aran: Naut Aran, vall de Ruda, cap al Pontet de Ruda, CH3128, 1495 m, surgències d'aigua carbonatada al costat del riu, 12-IX-2017.

Espècie que en l'actualitat és protegida legalment a Catalunya, i de la qual només se'n coneixen dues o tres localitats recents a l'alta muntanya de l'Aran i del Pallars (Bolòs et al., 1997; Carrillo \& Vigo, 2002; Ninot et al., 2010; Aymerich, 2013a). A més, es disposa de citacions antigues en localitats de l'Aran d'altitud moderada (Coste \& Soulié, 1913) on sembla que no ha estat retrobada, i també a la mateixa vall de Ruda (Coste, 1922). Desconeixem la localitat precisa d'aquesta darrera citació, però podria correspondre al mateix indret on ara l'hem trobada, cas en el qual es tractaria de la confirmació actual d'una localitat antiga. Hi hem observat dues agrupacions separades per uns $50 \mathrm{~m}$, amb una població total estimada entre 50 i 100 individus.

Descurainia suffruticosa (Coste \& Soulié) Aymerich \& L. Sáez [D. tanacetifolia (L.) Prantl. subsp. suffruticosa (Coste \& Soulié) Jauzein; Hugueninia tanacetifolia (L.) Rchb. subsp. suffruticosa (Coste \& Soulié) P.W. Ball]

PALlars SobIRÀ: Lladorre, tram inferior del torrent de Mascaró, abans de la confluència amb el riu de Tavascan. CH5526, 1360-1370 m, herbassars humits als marges del torrent, 3-X-2014.

Endemisme pirenaico-cantàbric en general escàs, i qualificat com a NT (Quasi amenaçat) a Catalunya (Sáez et al., 2010), on es limita a l'Aran i a l'alt Pallars. Fins ara totes les citacions pallareses eren de les valls de l'alt Àneu. Amb aquesta dada n'ampliem la distribució coneguda a la vall de Cardós. Sáez \& Aymerich (2017) aporten dades que justifiquen el reconeixement d'aquest tàxon en rang específic.

Dryopteris borreri (Newman) Oberh. \& Tavel

Pallars SobIrÀ: *Ribera de Cardós, Estaon, cap a la borda de Gori, CH5317, $1320 \mathrm{~m}$, arbreda caducifòlia vora l'aigua, 2-X-2014.

Confirmem la presència al Pallars d'aquest tàxon, on no va ser indicat a l'atles pteridològic de Catalunya (Sáez, 1997) malgrat l'existència de tres citacions prèvies (Gruber, 1974, 1978; Bolòs, 1998). Desconeixem la fiabilitat d'aquelles citacions, i certament les de Gruber haurien de ser reconsiderades, perquè les errades no són excepcionals als inventaris fitocenòlogics d'aquest autor.

Eleocharis mamillata (H. Lindb. fil.) H. Lindb. fil. subsp. austriaca (Hayek) Strandh.

PALlars SobIRÀ: *Alt Àneu, capçalera de la vall d'Àrreu, clot de Rialba superior, CH3725, 2090 m, bassa temporal dins una àmplia depressió torbosa, 26-VIII2016.

Oròfit europeu que gairebé no ha estat citat als Pirineus, possiblement perquè sovint s'ha confós amb E. palustris, de la qual només es diferencia bé en estat fructífer. Només en coneixem tres citacions catalanes, que provenen de localitats poc apartades de la que ara indiquem, en hàbitats torbosos de l'alt Pallars i l'Aran 
(Perdigó, 1983; Luceño \& Jiménez-Mejías, 2006; Ninot et al., 2010). Al clot de Rialba era una planta escassa i localitzada, representada per pocs individus limitats a un petit sector d'aquest complex de torberes. No va ser inclosa al Llibre vermell de la flora catalana per Sáez et al. (2010), però va ser catalogada com a CR (En perill crític) a la Lista roja espanyola (Moreno, 2011).

Epipactis fageticola (C.E. Hermos) Devillers-Tersch. \& Devillers PALLARS SOBIRÀ: Rialp, riu Romadriu sota el poble homònim, CH5601, 1290 m, bosc de ribera, 17-VIII-2017 (en fruit).

Orquídia de distribució encara mal coneguda a Catalunya, que al Pallars ja havia estat indicada a la vall de Tor (Aymerich \& Fernández, 2013), en un hàbitat molt similar al del Romadriu.

Gagea villosa (M. Bieb) Sweet

Pallars Sobirà: Llavorsí, la Colomina, CH5305, 950 m, marge d'un prat, 13-III-2017; Ribera de Cardós, afores del poble, CH5413, 895 m, marge de camí, 13-III-2017.

Espècie molt rara a les valls pirinenques del Pallars, on tan sols en coneixem una citació prop de Rialp (Carreras, 1993). A les dues localitats que aportem hi vam veure molt pocs individus, menys de deu en cadascuna.

\section{Geranium phaeum L.}

PALlars Sobirà: Rialp, barranc de Pamano al pont d'Altron, CH4301, 1000 m, vorada d'una arbreda de caducifolis dominada per Fraxinus excelsior, 29-V-2017.

Planta lligada a boscos humits que és molt rara a Catalunya fora de l'Aran (BDBC). Al Pallars era coneguda de diversos punts de l'alt Àneu que presenten alguna influència atlàntica, amb límit sud a Esterri. Aquesta nova localitat de la vall d'Àssua amplia la distribució coneguda força més cap al sud. Hi vam observar un nucli localitzat en pocs metres quadrats, però molt dens, amb desenes d'individus.

Gymnadenia densiflora (Wahlenb.) A. Dietr.

Aran: *Naut Aran, Bagergue, cap al Plan de Moredo, CH2735, 1840-1880 m, molleres basòfiles i herbassars de Molinia coerulea basòfils, 6-VII-2017; *Naut Aran, Pales de Ruda, CH3326, 1790 m, herbassar higròfil en un talús, sobre roca calcària, 6-VII-2017; Pallars SobIRÀ: *Alt Àneu, Alós d'Isil, vora el riu Noguera Pallaresa al pont de l'Escala Alta, CH4533, 1395 m, mollera basòfila, 8-VII-2017; Alt Àneu, Alós d'Isil, cap a la borda de Socampo, CH4532, 1385 m, herbassar higròfil en un talús de roca calcària, 8-VII-2017; Alt Urgell: *la Vansa i Fórnols, serra del Cadí, Pradell, CG8082, 1970-1990 m, molleres basòfiles, 14-VII-2017.

Gymnadenia densiflora és una espècie no reconeguda a les flores de referència actualment vigents al nostre territori (Bolòs \& Vigo, 2001; Bolòs et al., 2005; Aedo, 2005), que la consideren sinònim de G. conopsea L.. Tot i això, existeixen evidències d'una diferenciació genètica, cromosòmica, morfològica, fenològica i ecològica entre els dos tàxons (Marhold et al., 2005; Campbell et al., 2007; Stark 
et al., 2011) i la seva acceptació ja és molt generalitzada entre els botànics europeus. Darrerament sí que sol ser tinguda en compte en els cercles orquidiològics catalans, cosa que ha generat algunes citacions explícites al Ripollès i el Berguedà (Canals et al., 2016; GOC, 2017). Tot i que els testimonis fotogràfics suggereixen que almenys part d'aquestes citacions deu ser correcta, existeix incertesa sobre la fiabilitat dels criteris que es van fer servir per a separar $G$. densiflora de G. conopsea, ja que sovint s'insisteix en la mida de la planta i la densitat de la inflorescència, mentre que s'obvien altres caràcters probablement més consistents. D'altra banda, treballs citològics (Trávníček et al., 2012) — vegeu més avall— han posat de manifest que als Pirineus el grup de G. conopsea és especialment complex, amb diversos nivells de ploïdia i citotips, situació que fa necessaris nous treballs per aclarir la taxonomia del grup.

Amb aquesta nota ens limitem a constatar i comentar l'existència als Pirineus catalans de plantes que per les seves característiques morfològiques —així com per l'ecologia i la fenologia- concorden en general amb les G. densiflora d'Europa central, motiu pel qual considerem que aquesta espècie ha de ser acceptada per a la flora catalana, almenys provisionalment. Aquesta acceptació no exclou la possibilitat que les «G. densiflora morfològiques» pirinenques puguin ser en realitat un tàxon diferent encara no descrit, que en principi correspondria al grup anomenat «French diploid» del treball de Trávníček et al. (2012), aparentment estès per l'àrea pirinenca i l'oest de França. Caràcters que fan referibles les plantes de les localitats indicades a $G$. densiflora són sobretot les flors nombroses i disposades en inflorescència densa, els labels més amples que llargs i amb lòbuls laterals més amples que el lòbul mitjà, i la presència de 4-7 fulles basals, les més grosses de les quals depassen en general els $2 \mathrm{~cm}$ d'amplada. Altres caràcters habituals en aquestes poblacions pirinenques són el color rosa intens de les flors, les bràctees amples i d'aspecte foliaci i una relació entre la llargada del label i de l'ovari al voltant d'1,5 (1,3-1,6), mentre que en $G$. conopsea aquesta relació és habitualment superior a 2; cal dir que aquest darrer caràcter ja havia estat assenyalat per a $G$. densiflora en obres antigues (Bonnier, 1990), però sovint no és indicat en treballs recents. Aquestes Gymnadenia estan molt lligades a herbassars higròfils i basòfils (molleres alcalines i ambients afins), que són l'hàbitat característic de G. densiflora a l'Europa mitjana. La fenologia de floració, des de la fi de juny fins a primers d'agost, també coincideix amb la de les G. densiflora típiques; habitualment comencen a florir quan les Dactylorhiza d'aquestes molleres ja presenten flors pansides.

Tot i trobar-se lluny de l'àrea d'estudi, hem inclòs en aquesta nota també una localitat de l'Alt Urgell, perquè mereix un comentari especial. En aquesta mateixa localitat es va fer una de les dues citacions catalanes de G. odoratissima (L.) L.C.M. Richard que habitualment s'han considerat fiables (Carreras et al., 1995). Després d'anys d'intentar relocalitzar-hi aquesta espècie molt rara, en el marc d'actuacions promogudes pel Parc Natural del Cadí-Moixeró, hem arribat a la conclusió que el més probable és que es confongués amb G. densiflora. Aquesta és l'única Gymnadenia que en els darrers temps hem observat a la localitat, on és força abundant, viu en els mateixos hàbitats en què es va citar G. odoratissima i 
sovint encara presenta alguns individus amb flors a la fi de juliol o primers d'agost ( $G$. odoratissima hi va ser indicada a l'inici d'agost). És possible que es produís una confusió a causa dels esperons relativament curts de les flors basals d'aquestes $G$. densiflora pirinenques, més curts proporcionalment que els de la resta de flors i que sovint fan només 1,3 vegades la llargada de l'ovari, cosa que podria fer pensar en $G$. odoratissima. Atès que $G$. odoratissima és una planta actualment protegida a Catalunya i que va ser qualificada com a CR (En perill crític) per Sáez et al. (2010), considerem necessari excloure aquesta localitat del Cadí, a no ser que s'obtinguin noves dades en sentit contrari. L'altra localitat catalana considerada fiable d'aquesta espècie, al massís del Catllaràs (Berguedà), sí que ha estat confirmada, i la població va ser retrobada l'any 2104 per Esteve Sais, després de tres dècades sense observacions; aquestes plantes corresponen a les formes del sud-oest d'Europa d'esperons relativament llargs, que probablement han de ser tractades com a espècie diferent i que han estat anomenades G. odoratissima subsp. longicalcarata C.E. Hermos. \& Sabando o referides al nom d'atribució incerta G. pyrenaica (Philippe) Giraudias.

\section{Linum tenuifolium L.}

Pallars Sobirà: Baiasca, a l'oest de la borda Pergavatx, CH4708, 1360 m, pastura xeròfila en un vessant rocós d'esquistos carbonatats orientat al sud, 21-V-2015.

Espècie molt rara als Pirineus catalans, on assoleix el seu límit sud-oest de distribució. Com a localitats més pròximes, ja era coneguda d'uns quants punts de les valls d'Espot i de Boí (Carrillo \& Ninot, 1992).

\section{Myriophyllum alterniflorum DC.}

Pallars Jussà: la Torre de Cabdella, estany de Filià, CH3101, 2130 m, estany mesotròfic, 28-VIII-2017.

Aquesta espècie ja va ser citada a l'estany de Filià per Pineda (1986), però aquesta observació no és acceptada o es considera dubtosa a les bases de dades florístiques de referència (BDBC, AFP). Confirmem que és present en aquesta localitat, que representa el seu límit meridional als Pirineus; aquesta espècie és comuna una mica més al nord, als estanys d'alta muntanya de la confluencia del Pallars, l'Aran i la Ribagorça.

Persicaria minor (Huds.) Opiz

Pallars Sobirà: *Alt Àneu, cua de l'embassament de Borén, CH4294, 1095 m, sòls temporalment inundats a la franja de fluctuació del nivell d'aigua de l'embassament, 13-IX-2017; *la Guingueta d'Àneu, riba est de l'embassament de la Torrassa, CH4616, 935 m, marge fangós de l'embassament, 13-IX-2017.

Planta descoberta fa pocs anys a Catalunya, a la Cerdanya, de la qual fins ara només es coneixien dues poblacions (Aymerich, 2014). Les noves localitats del Pallars són probablement el resultat d'una colonització recent, ja que no hi havia estat observada en visites d'anys previs; concretament, a Borén es fa al mateix punt en què es troba la Rorippa sylvestris comentada més avall, que hi va ser detectada ja l'any 2013, i en aquesta data no es va observar Persicaria minor. La 
població local de Borén era nombrosa, amb uns quants centenars de plantes, mentre que a la Torrassa n'hi vam veure menys de deu.

Potamogeton alpinus Balb.

Pallars SobIrà: *la Guingueta d'Àneu, embassament de la Torrassa, CH4616, $930 \mathrm{~m}$, dins l'embassament, 13-IX-2017.

Localitat interessant per l'altitud inusualment baixa per a aquesta espècie boreoalpina, que al sud d'Europa està en general limitada a l'alta muntanya. $P$. alpinus és relativament freqüent als estanys de la confluència del Pallars, l'Aran i la Ribagorça, però sempre als estatges subalpí i alpí, per sobre dels 1900 m (BDBC, AFP). Al sud d'Europa hi ha citacions excepcionals a només $140 \mathrm{~m}$ als Alps italians, a la Llombardia (Lastrucci et al., 2010), i a $700 \mathrm{~m}$ a la península Ibèrica, a Navarra (García Murillo, 2010). Desconeixem l'abundància i el grau d'implantació d'aquesta espècie a la Torrassa, perquè l'observació es limita a un fragment arrencat $\mathrm{i}$ arrossegat per la corrent fins a la riba de l'embassament.

\section{Potamogeton natans L.}

Pallars SobirÀ: Alt Àneu, port de la Bonaigua, estanyet del Cap del Port, CH3425, 2070 m, estanyol mig reblert, acompanyada de P. berchtoldii Fieber, 15-VI-2017.

Espècie que no havia estat citada del Pallars. Es tracta d'una colonització molt recent, ja que no havia estat observada en aquesta localitat en anys previs. És probable que hagi arribat al port de la Bonaigua transportada per ànecs des d'alguna de les poques localitats araneses d'aquest Potamogeton, potser des de la Bassa Nera de la vall d'Aiguamòg, situada a poc més de $5 \mathrm{~km}$. Aquesta planta és, en general, molt rara a Catalunya (Sáez et al., 2010), però els darrers temps sembla en clara expansió, dinàmica que s'ha constatat sobretot a la conca del Llobregat (Aymerich, 2012).

Potamogeton $\times$ nitens Weber $[P$. gramineus L. $\times$ P. perfoliatus L.]

Pallars Jussà: *la Torre de Cabdella, estany de Filià, CH3101, 2130 m, estany mesotròfic, 28-VIII-2017.

Primera citació concreta d'aquest tàxon per a la flora catalana, segons la informació disponible. Bolòs \& Vigo (2001) indiquen vagament aquest híbrid en una nota final a l'apartat del gènere Potamogeton, però no sabem que se n'hagi publicat cap localitat i sembla que no es pot excloure que el comentari es basi en l'extrapolació d'observacions fetes als Pirineus aragonesos, on sí que havia estat indicat d'un parell d'estanys d'alta muntanya del sector aragonès (Montserrat, 1981). Els híbrids interespecífics representen una part important de la diversitat taxonòmica del gènere Potamogeton (Kaplan, 2010) i sovint tendeixen a formar poblacions independents de les espècies parentals. Aquests híbrids són freqüents i ben coneguts en regions nòrdiques i temperades d'Euràsia, però han estat molt poc citats a l'àrea mediterrània i, concretament, a la península Ibèrica se n'han indicat tres (García Murillo, 2010) i a Catalunya només un amb seguretat, $P . \times$ salicifolius $(P$. perfoliatus $\times P$. lucens) (Aymerich et al., 2014). Considerem que les plantes de Filià són referibles a $P . \times$ nitens per diverses característiques 
morfològiques: tiges ramificades, de secció circular; fulles semiaplexicaules, petites (fins a 5 x 1,5 cm), ovato-lanceolades, en general una mica plegades longitudinalment, d'àpex agut o subagut, amb 7-13 nervis i marges denticulats de forma fina i irregular; estípules persistents abundants, almenys a la meitat apical de les tiges, de 0,9-1,3 cm de longitud. En la data de la visita, P. ×nitens va ser l'únic Potamogeton que vam observar a l'estany de Filià, on era relativament abundant i creixia en companyia d'altres hidròfits (Sparganium angustifolium, Myriophyllum alterniflorum, Ranunculus $c f$. aquatilis). Prèviament, en aquest estany hi havia estat citat $P$. crispus L. (Pineda, 1986), informació que és recollida a les bases de dades florístiques de referència (BDBC, AFP), però ens sembla altament probable una confusió amb $P$. ×nitens.

Ranunculus penicillatus (Dumort.) Bab. subsp. pseudofluitans (Syme) S.D. Webster

Pallars Sobirà: Ribera de Cardós, riu Noguera de Cardós al sud del poble, CH5410-5411-5412, 850-870 m, dins l'aigua en trams de corrent poc fort i llera de graves i llims, 3-X-2013.

Tàxon poc citat a Catalunya, on es coneix sobretot a la conca del Llobregat i a les comarques del nord-est (BDBC; Aymerich, 2013b), mentre que als rius pirinencs ha estat indicat puntualment al Segre (Aymerich, 2013b). No en coneixem cap dada prèvia al Pallars o l'Aran. Cal precisar que a les bases de dades (BDBC, AFP) apareix una presumpta indicació de $R$. penicillatus a l'estany de Sant Maurici (vall d'Espot), però aquesta dada realment correspon a una citació de $R$. fluitans L. —un tàxon inexistent a Catalunya — deguda a Llensa (1947), recollida després per Carrillo \& Ninot (1992) i que és d'atribució molt incerta, ja que podria correspondre a qualsevol tàxon de Ranunculus del subgènere Batrachium. Es probable que també corresponguin a $R$. penicillatus plantes que hem observat en alguns punts dels rius Noguera Pallaresa (sota Esterri) i Noguera de Vallferrera (sota Araós), d'aspecte molt similar a les de la vall de Cardós, però no ho hem pogut confirmar per manca de material suficient per a la identificació.

\section{Rorippa islandica (Oeder) Borbás}

Pallars Jussà:* la Pobla de Segur, confluència del riu Flamisell amb l'embassament de Sant Antoni, CG3278, 500 m, marge fangós de l'embassament, 2-X2017; Pallars Sobirà: *la Guingueta d'Àneu, riba est de l'embassament de la Torrassa, CH4616, 935 m, marge fangós de l'embassament, 13-IX-2017.

Localitats de baixa altitud d'aquesta espècie àrticoalpina habitualment lligada als ambients d'alta muntanya, i que en la revisió de Flora iberica (Martínez Laborde, 1993) només es va acceptar que es troba per damunt dels 1600 m. La del Pallars Jussà no és cap novetat, ja que hi va ser indicada fa temps (Benedí et al., 1986), però hem considerat convenient ratificar la presència actual d'aquesta planta a la zona, a causa de les freqüents confusions entre $R$. islandica i $R$. palustris (L.) Besser, que dificulten la interpretació de les informacions abocades a les bases de dades florístiques del territori (BDBC, AFP). R. palustris també és coneguda a l'embassament de Sant Antoni (Sáez et al., 2008) i l'hi hem observat 
abundant en alguns sectors, de manera que aquesta localitat seria una de les poques en què coincideixen aquestes dues espècies morfològicament similars.

Rorippa sylvestris (L.) Besser

Pallars SobIrà: *Alt Àneu, cua de l'embassament de Borén, CH4294, 1095 m, sòls temporalment inundats a la franja de fluctuació del nivell d'aigua de l'embassament, 3-X-2013.

Espècie que no havia estat citada al Pallars Sobirà ni a les valls pirinenques pròximes, amb l'excepció de l'alt Segre (BDBC, AFP). Sí que es coneixia de l'embassament de Sant Antoni al Pallars Jussà (Molero \& Romo, 1988), on també l'hem observada recentment.

\section{Salix lapponum L.}

La presència de Salix lapponum en algunes localitats del Pallars es coneix des de fa temps a la vall Ferrera (Vigo \& Carreras, 1987) i més endavant a la de Cardós (Aymerich, 1998), i encara més tard va ser detectat també a la capçalera del riu Noguera Pallaresa en territori de l'Aran (Pérez-Haase, 2005). Aquestes observacions, reflectides en cartografies d'escala poc detallada, poden generar la percepció errònia que és una planta no especialment rara en aquest sector dels Pirineus centrals, quan en realitat és molt escassa i té una situació força complexa. Desconeixem detalls de la població aranesa, però un estudi dels quatre nuclis del Pallars, fomentat pel Parc Natural de l'Alt Pirineu, ha posat de manifest que més que no pas de poblacions s'hauria de parlar d'individus isolats de sexe masculí. A la vall Ferrera se'n coneix una sola taca clonal, de sexe masculí. A la vall de Cardós, de les 3-7 taques conegudes a la vall de Romedo-Senó, s'ha pogut determinar el sexe de tres i són també masculines; no es pot excloure que, en aquesta vall, totes les taques provinguin de la fragmentació d'un sol individu masculí inicial. No ha estat possible determinar el sexe de l'única taca coneguda als estanys de Guiló, també a la vall de Cardós. La hipòtesi més plausible és que aquests petits nuclis del Pallars s'hagin format per colonitzacions esporàdiques, degudes al transport de llavors a distàncies llargues pel vent o per animals. A banda d'aquests nuclis atribuibles clarament a S. lapponum, al llarg del riu de Baiau s'observen individus amb indicis d'hibridació entre $S$. lapponum i S. bicolor, bé que els caràcters dominants són d'aquest darrer. Atès que es tracta d'una planta legalment protegida a Catalunya (Annex 2 del Catàleg de flora amenaçada) aquesta situació planteja un repte per a la gestió, ja que la persistència local de l'espècie dependria únicament del manteniment o l'expansió vegetativa de les taques actuals, sense que aparentment sigui possible el reclutament per reproducció sexual. Aquesta situació no sembla exclusiva dels nuclis pallaresos de l'espècie, sinó que també s'ha observat en localitats de l'oest d'Andorra (dades de la xarxa FloraCat, de collaboració transfronterera sobre flora patrimonial), mentre que les veritables poblacions formades per diversos individus masculins i femenins semblen limitades a zones més orientals dels Pirineus, on es concentra la distribució regional d'aquesta espècie. 


\section{Saponaria bellidifolia Sm.}

PAllars SobIRÀ: Alt Àneu, vall superior de la Noguera Pallaresa entre els barrancs de Llançanes i de Marimanya, CH3935, 1590-1595 m, aflorament de roca calcària amb coberta vegetal feble, 1-VII-2013

Planta molt rara als Pirineus, on fins ara es coneixien cinc localitats (Lavaupot et al., 2011; Aymerich, 2013a). A Catalunya es considera amenaçada (Sáez et al., 2010) i té protecció legal. La població d'aquesta nova localitat, formada per unes 50 plantes reproductores, és petita si es compara amb l'altra que es coneix al Pallars (Valaran, també a l'alt Âneu) i que és la més important dels Pirineus, però té unes dimensions no gaire diferents a les de les localitats conegudes al sector francès de la serralada.

Sempervivum $\times$ fauconnettii Reut. [S. tectorum L. $\times$ S. arachnoideum L.] Aran: Naut Aran, Bagergue, cap al Plan de Moredo, CH2735, 1890 m, roques calcàries, 6-VII-2017; PALlars Jussà: la Torre de Cabdella, vall de Filià, barranc de la coma de les Fuses, CH3103, 1930 m, roques silícies, 28-VIII-2017; PALLARS SobIRÀ: Alt Àneu, vessant est del pic de Qüenca, CH4129, 2230-2320 m, roques calcàries, 25-VII-2014; Alt Àneu, vall superior de la Noguera Pallaresa entre els barrancs de Llançanes i de Marimanya, CH3935, 1590 m, roca calcària, 1-VII-2013.

Els híbrids interespecífics de Sempervivum han merescut una atenció escassa als Pirineus, tot i que en alguns sectors representen una part important de les poblacions. $S$. ×fauconnettii és el tàxon hibridogen que mostra més autonomia, ja que és habitual que faci poblacions en absència d'una de les espècies parentals o de les dues. A Catalunya ha estat indicat sobretot a les muntanyes calcàries dels Pirineus orientals, on és un dels Sempervivum més estesos (Vigo et al., 2003; Aymerich \& Sáez, 2015). Als Pirineus centrals havia estat assenyalat de forma explícita d'un indret de l'alt Pallars (Aymerich, 2013c). Amb aquesta nota ampliem el nombre de localitats conegudes en aquest sector, que es concentren a les zones calcàries del límit Pallars-Aran.

Sisymbrella aspera (L.) Spach. subsp. aspera

Pallars Jussì: Conca de Dalt, riba est de l'embassament de Sant Antoni, cap a l'aiguabarreig amb el barranc de Claverol, CG3277, $500 \mathrm{~m}$, zones fangoses a la franja de fluctuació de l'aigua de l'embassament, 9-III-2017; PALLARs SobIRÀ: Rialp, Llessui, antiga estació d'esquí, CH4041, 1445 m, zona d'aparcament de vehicles, 29-V-2017.

Noves localitats d'aquest tàxon poc citat al Pallars (Carreras, 1993; BDBC, AFP).

\section{Sorbus torminalis (L.) Crantz}

Pallars Sobirà: Soriguera, barranc de Roca Gran, CG4491, 950 m, bosc de Pinus sylvestris, 2-X-2017.

Espècie molt rara als Pirineus centrals catalans, de la qual no ens consta cap citació al Pallars Sobirà, tot i que sí que havia estat assenyalada puntualment d'algunes serres del Pallars Jussà i l'Alt Urgell (BDBC, AFP). L'observació de Soriguera es refereix a un sol individu. 


\section{Thalictrum simplex L.}

Aran: Naut Aran, vall del riu Aiguamòg per damunt de la borda de Servat, CH2926, $1520 \mathrm{~m}$, prat de dall humit, 5-VII-2017.

Tàxon no citat fins ara de l'Aran, segons la informació disponible, i que tampoc era conegut al conjunt dels Pirineus atlàntics (BDBC, AFP). Les localitats més pròximes es troben al Pallars, concretament a la vall de Santa Magdalena (Carreras, 1993).

Trocdaris verticillatum (L.) Raf. [Carum verticillatum (L.) W.D.J. Koch] PAllars SobIrà: Alins, Àreu, riba esquerra del riu Noguera de Vallferrera sota la borda del Puntanou, CH6219, 1410 m, jonquera acidòfila, 9-VII-2015.

Espècie molt rara a Catalunya, qualificada com a NT (Quasi amenaçada) per Sáez et al. (2010) i que al Pallars sembla tenir una única localitat. Aquesta localitat es va publicar amb poc detall a l'atles ORCA (Bolòs et al., 1999), indicant-ne tan sols el quadrat UTM de 10x10 km CH62, i és recollida per les bases de dades de referència $(\mathrm{BDBC}, \mathrm{AFP})$. Atès l'interès conservacionista d'aquesta planta, considerem convenient proporcionar informació més concreta sobre la seva localització a la zona. L'origen d'aquella citació és un plec d'herbari recol-lectat l'any 1990 per J. Vigo i conservat a l'herbari BCN, en el qual s'indica com a localitat «Vallferrera, font Roja» i una altitud de $1400 \mathrm{~m}$. Segons les coordenades facilitades a la base de dades de l'herbari BCN, aquest lloc quedaria poques desenes de metres més al sud de la localitat que nosaltres indiquem, motiu pel qual es pot considerar que es tractaria de la mateixa població. Fem notar, en tot cas, que l'UTM de 10x10 km és CH61 i no pas CH62, diferència que possiblement es pot atribuir als canvis recents en els sistemes de referència utilitzats per la cartografia oficial.

Tulipa sylvestris subsp. australis (Link.) Pamp.

Aran: Naut Aran, Beret, sobre les fonts del riu Malo, CH3230, 1870 m, prat nitrificat, 1-VII-2013; Pallars SobIRÀ: Alt Àneu, Alós d'Isil, vessant a l'oest del riu Noguera Pallaresa, cap a les bordes de Pina, CH4531, 1335 m, relleixos de roques, 26-VI-2012.

No coneixem citacions prèvies d'aquesta espècie a l'Aran, tot i que sí que es coneixia en indrets pròxims del Pallars i del territori francès. Al Pallars Sobirà és molt rara i està documentada sobretot de la vall de Santa Magdalena (Carreras, 1993), mentre que a la part septentrional de la comarca només se n'havia publicat una localitat al sector de Bonabé (Aymerich \& Sáez, 2015), corresponent a una petita població temporal que aparentment ja ha desaparegut.

\section{Vicia orobus DC.}

Pallars Sobirà: Alins, bosc de la Font Tallada, CH6720, 1800 m, vorada d'una avetosa, 9-VII-2014.

Espècie d'afinitat atlàntica que apareix de forma esparsa i escassa al Pallars, sobretot a la vall de Cardós (BDBC, AFP). Segons la informació disponible, no havia estat indicada encara de la vall Ferrera, on se situa la nova localitat. 
Vinca minor L.

Pallars Sobirà: Soriguera, Arcalís, bosquet de Saleretes, CG4391, 900 m, bosc de Pinus nigra i P. sylvestris, 2-X-2017.

Planta que no havia estat citada dels Prepirineus centrals catalans (BDBC, $\mathrm{AFP})$, però sí que era coneguda d'algun punt del sector nord del Pallars Sobirà. Com passa en moltes localitats catalanes de l'espècie, es fa difícil determinar si es tracta d'una població autòctona o bé resulta d'una introducció; tot i que es fa en un hàbitat natural i apartat de construccions actuals o desaparegudes, considerem que el més probable és que el nucli de Soriguera tingui l'origen en un ús antic com a planta ornamental.

Xanthoselinum venetum (Spreng.) Soldano \& Banfi [Peucedanum alsaticum L. subsp. venetum (Spreng.) Rouy \& E. G. Camus]

Pallars SobIRÀ: *Sort, voltants de Montardit de Dalt, CG4395-4495, 880-980 m, marges de prats i bardisses, 8-IX-2017.

Novetat interessant per a la flora dels Pirineus centrals, on fins ara no es coneixia (BDBC; AFP). Aquesta localitat representa, aparentment, el límit occidental absolut d'aquesta espècie sud-europea. Localment hi és força abundant i ocupa una àrea relativament extensa. Es troba, de forma molt local i escassa, a la Catalunya oriental, i les localitats més pròximes es situen al Bages (Bolòs et al., 1999).

\section{Agraïments}

Algunes de les informacions exposades en aquest article s'han obtingut amb la realització de treballs promoguts pels parcs naturals de l'Alt Pirineu i del Cadí-Moixeró.

\section{Referències bibliogràfiques}

Aedo, C. 2005. Gymnadenia R. Br. In: Aedo, C.; Herrero, A. (eds.). Flora iberica. Vol. XXI. Smilacaceae-Orchidaceae: 82-85. Real Jardín Botánico-CSC. Madrid.

AFP. Atles de la Flora dels Pirineus: <http://www.atlasflorapyrenaea.org>.

Aymerich, P. 1998. Aportació al coneixement florístic del nord de Catalunya. Butll. Inst. Catalana Hist. Nat. 66: 41-57.

Aymerich, P. 2008. Notes florístiques de l'alt Pallars. Acta Bot. Barcinon. 51: 17-33.

Aymerich, P. 2012. Potamogeton i Zannichellia a la conca mitjana del riu Llobregat (Catalunya, NE de la península Ibèrica). Orsis 26: 57-89.

Aymerich, P. 2013a. Notes sobre algunes plantes, rares o amenaçades als Pirineus catalans. Butll. Inst. Catalana Hist. Nat.77: 5-26.

Aymerich, P. 2013b. Contribució al coneixement florístic del territori ausosegàrric (NE de la península Ibèrica). Orsis 27: 209-259.

Aymerich, P. 2013c. Sempervivum tectorum x S. arachnoideum. In: Anuari Naturalista del Parc Natural de l'Alt Pirineu 2012: 13.

Aymerich, P. 2014. Notes florístiques de les conques altes dels rius Segre i Llobregat (II). Orsis 28: 7-47.

Aymerich, P.; Fernández, J. 2013. Epipactis fageticola. In: Anuari Naturalista del Parc Natural de l'Alt Pirineu 2012: 12. 
Aymerich, P.; Guardiola, M.; Petit, A.; Ballesteros, E.; Chappuis, E. 2014. Distribució, ecologia i conservació de Potamogeton lucens i P. schweinfurthii a Catalunya. Butll. Inst. Catalana Hist. Nat. 78: 25-37.

Aymerich, P.; Sáez, L. 2015. Comentaris i precisions previs a la Checklist de la flora de Catalunya (nord-est de la península Ibèrica). Orsis 29: 1-68.

Benedí, C.; Molero, J.; Romo, A.M. 1986. Aportacions a la flora dels Prepirineus centrals catalans. Collect. Bot. (Barcelona) 16: 383-390.

BDBC. Banc de Dades de Biodiversitat de Catalunya. <http://biodiver.bio.ub.es/biocat/>.

Bolòs, O. 1998. Orca: Atlas Corològic. Primera compilació general. Secció Ciències Biològiques. Institut d'Estudis Catalans.

Bolòs, O.; Font, X.; Pons, X.; Vigo, J. (Eds.). 1997. ORCA. Atlas corològic de la flora dels Països Catalans 7. Institut d'Estudis Catalans (Sec. Ciències Biològiques). Barcelona.

Bolòs, O.; Font, X.; Vigo, J. (Eds.). 1999. ORCA. Atlas corològic de la flora dels Països Catalans 9. Institut d'Estudis Catalans (Sec. Ciències Biològiques). Barcelona.

Bolòs, O.; Vigo, J. 2001. Flora dels Països Catalans. Vol. 4. Ed. Barcino. Barcelona.

Bolòs, O.; Vigo, J.; Masalles, R.M; Ninot, J.M. 2005. Flora Manual dels Països Catalans. $3^{\mathrm{a}}$ edició. Ed. 3. Pòrtic. Barcelona.

Bonnier, G. 1990. Flore complète illustrée en couleurs de France, Suisse, Belgique et pays voisins. Ed. Belin. Paris.

Bou, J.; Manobens, R.M. 1982. Botrychium matrichariifolium als Pirineus. Collect Bot. (Barcelona) 13(1): 37-41.

Campbell, V.V.; Rowe, G.; Beebee, T.J.C.; Hutchings, M.J. 2007. Genetic differentiation amongst fragrant orchids (Gymnadenia conopsea s.l.) in the British Isles. Bot. J. Linn. Soc. 155: 349-360. <https://doi.org/10.1111/j.1095-8339.2007.00709.x>

Canals, J.; Gonzàlez, F.; Hernàndez, J. (coord.) 2016. Orquídies del Ripollès. Institució Catalana d'Història Natural. Barcelona.

Carreras, J. 1993. Flora i vegetació de Sant Joan de l'Erm i de la vall de Santa Magdalena (Pirineus catalans). Col. Estudis, 3. Institut d'Estudis Ilerdencs. Lleida.

Carreras, J.; Carrillo, E.; Font, X.; Ninot, J.M.; Soriano, I.; Vigo, J.. 1995: La vegetació de les serres compreses entre els rius Segre i Llobregat. 2-Comunitats herbàcies higròfiles, fissurícoles i glareícoles. Butll. Inst. Catalana Hist. Nat. 63: 51-83.

Carrillo, E.; Ninot, J.M. 1992. Flora i vegetació de les valls d’Espot i de Boí. Arxius de la Secció de Ciències, 99(2). Institut d'Estudis Catalans. Barcelona.

Carrillo, E.; Vigo, J. 2002. Mapa de vegetació de Catalunya 1:50.000. Isil 149 (33-8). Memòria. Institut d'Estudis Catalans. Barcelona.

Coste, H. 1922. Supplément de la Florule du Val d'Aran. Le Monde des Plantes 23-137: 6-8. 3e série.

Coste, H.P.; Soulié, J. 1913. Catalogue des plantes ou florule du Val d'Aran. Bull. Géogr. Bot. 23: 91-208.

García Murillo, P. 2010. Potamogeton L. In: Talavera, S.; Gallego, M.J.; Romero, C.; Herrero, A. (Eds.) Flora iberica Vol. XVIII. Butomaceae-Juncaceae: 64-85. Real Jardín Botánico-CSIC. Madrid.

GOC. 2017. Resum de les sortides de l'associació (2011-2015). Butll. Grup Orquidiològic Catalunya 1:29, 30.

Gruber, M. 1974. Les forêts de Quercus pubescens Willd., de Quercus rotundifolia Lam. et les garrigues à Quercus coccifera L. des Pyrénées catalanes. Bull. Soc. Hist. Nat. Toulouse 110: 141-156. 
Gruber, M. 1978. La végétation des Pyrénées ariègeoises et catalanes occidentales. Thèse. Université Aix-Marseille III.

Guardiola, M.; Petit, A.; Aymerich, P.; Pérez-Haase, A.; Mercadé, A.; Batriu, E.; Blanco-Moreno, J.M.; Illa, E.; Grau, O.; Carrillo, E.; Ninot, J.M. 2011. Coneixem bé la flora pirinenca? Els Pirineus catalans occidentals segueixen sorprenent. Actes del IX Col-loqui Internacional de Botànica Pirenaico-Cantàbrica a Ordino, Andorra: 181-190.

Kaplan, Z. 2010. Hybridization of Potamogeton species in the Czech Republic: diversity, distribution, temporal trends and habitat preferences. Preslia 82: 261-287.

Lastrucci, L.; Frignani, F.; Kaplan, Z. 2010. Potamogeton schweinfurthii and similar broad-leaved species in Italy. Webbia 65: 147-160.

Lavaupot, N.; Leblond, N.; Cambecèdes, J. 2011. La saponaire à feuilles de pâquerette (Saponaria bellidifolia Sm.) dans les Pyrénées françaises: historique de la connaissance et suivi des populations actuelles. Actes del IX Col-loqui Internacional de Botànica Pirenaico-cantàbrica a Ordino. Andorra: 241-248.

Llensa, S. 1947. Notas botánicas y forestales sobre la comarca del Alto Pallars (Pirineo Leridano). Anales Escuela Péritos 6: 267-288.

Luceño, M.; Jiménez, P. 2006. Algunas novedades coroológicas relevantes em ciperáceas ibéricas y baleáricas. Acta Bot. Malacitana 31: 230-231.

Marhold, K.; Jongepierová, I.; Krahulcová, A.; Kucera, J. 2005. Morphological and karyological differentiation of Gymnadenia densiflora and G. conopsea in the Czech Republic and Slovakia. Preslia 77: 159-176.

Martínez Laborde, J.B. 1993. Rorippa Scop. In: Castroviejo, S. et al. (eds.) Flora iberica Vol. IV. Cruciferae-Monotropaceae: 106-117. Real Jardín Botánico-CSIC. Madrid.

Molero, J.; Romo, A.M. 1988. Vegetación higronitrófila de los embalses del curso superior del Segre y de la Noguera Pallaresa. Acta Bot. Barcinon. 37: 289-296.

Montserrat, J. 1981. Notes sobre Potamogeton. Folia Bot. Misc. 2: 53-56.

Moreno, J.C. (coord.) 2011. Lista Roja de la Flora Vascular Española. Actualización con los datos de la Addenda 2010 al Atlas y Libro Rojo de la Flora Vascular Amenazada. Ministerio de Medio Ambiente - Sociedad Española de Biología de Conservación de las Plantas. Madrid.

Ninot, J.M.; Batriu, E.; Mercadé, A.; Pérez-Haase, A.; Carrillo, A.; Salvat, A. 2010. Flora vascular de les Planes de Son i la Mata de València. In: Germain, J. (coord.) Els sistemes naturals de les Planes de Son i la Mata de València. Treballs de la Institució Catalana d'Història Natural 16: 255-325.

Perdigó, M.T. 1983. L'Estanyó, un estany interessant a la Vall d'Aran. Collect. Bot. (Barcelona) 14: 511-514.

Pérez-Haase, A. 2005. Nova localitat de Salix lapponum L. als Pirineus. Butll. Inst. Catalana Hist. Nat. 73: 89-90.

Pié, G.; Vilar, L. 2014. Corologia de la flora vascular d'interès de conservació al Parc Natural del Montseny. Butll. Inst. Catalana Hist. Nat. 78: 65-74.

Pineda, L. 1986. Flòrula de la vall Fosca. Tesi de llicenciatura. Universitat de Barcelona.

Rivas-Martínez, S.; Báscones, J.C.; Díaz, T.E.; Fernández-González, F.; Loidi, J. 1991. Vegetación del Pirineo occidental y Navarra. Itinera Geobot. 5: 5-455.

Sáez, L. 1997. Atlas pteridològic de Catalunya i Andorra. Acta Bot. Barcinon. 44: 39-167.

Sáez, L.; Aymerich, P. 2017. New nomenclatural combinations in vascular plants. Orsis 31: 31-35.

$<$ https://doi.org/10.5565/rev/orsis.48> 
Sáez, L.; Molero, J.; Carrillo, E.; Ninot, J.M.; Guardiola, M.; Guàrdia, L.; Macías, C.; Aymerich, P. 2008. Noves contribucions al coneixement de la flora vascular del massís de Boumort (Prepirineus ibèrics, NE de la península Ibèrica). Orsis 23: 137-162.

Sáez, L.; Aymerich, P.; Blanché, C. 2010. Llibre Vermell de les plantes vasculars endèmiques i amenaçades de Catalunya. Ed. Argania. Barcelona.

Stark, C.; Michalski, S.G.; Babik, W.; Winterfeld, G.; Durka, W. 2011. Strong genetic differentiation between Gymandenia conopsea and G. densiflora despite morphological similarity. Pl. Syst. Evol. 293: 213-226. $<$ https://doi.org/10.1007/s00606-011-0439-x>

Trávníček, P. et al. [26 autors] 2012. Minority cytotypes in European populations of the Gymnadenia conopsea complex (Orchidaceae) greatly increase intraspecific and intrapopulation diversity. Ann. Bot. 110: 977-986. <https://doi.org/10.1093/aob/mcs171>

Vigo, J.; Carreras, J. 1987. Salix lapponum a la vall Ferrera. Butll. Inst. Catalana Hist. Nat. 54: 91.

Vigo, J.; Soriano, I.; Carreras, J.; Aymerich, P.; Carrillo, E.; Font, X.; Masalles, R.M.; Ninot, J.M. 2003. Flora del Parc Natural del Cadí-Moixeró i de les serres veïnes. Monografies del Museu de Ciències Naturals-Institut Botànic de Barcelona. 